\title{
Time trend analysis of HIV infection showing impact of national programs in an ICTC set up in a tertiary care hospital in North India
}

\author{
Gurleen Metha, Amanpreet Kaur, Gurpreet Singh, Sunil K Arora* \\ From 2nd International Science Symposium on HIV and Infectious Diseases (HIV SCIENCE 2014) \\ Chennai, India. 30 January - 1 February 2014
}

\section{Background}

The analysis of changing trend in the HIV infection with respect to various factors in a tertiary care hospital of North India in an ICTC (Integrated Counseling and Testing Centre) setting was studied.

\section{Materials and methods}

A total of 78,506 clients who visited the ICTC, PGIMER, Chandigarh from January 2003 to October 2013 were included and variables like age, sex, occupation, pattern of risk behavior and HIV sero status were studied. The patients were divided in three phases based on the phases of epidemic as evident from the variability in the positivity.

\section{Results}

Variable trend is seen in the HIV infection in last 11 years. The change in positivity rate in terms of age has affected all the age groups. In terms of profession, during third phase there is a decrease in the businessman and truckers group probably due to very effective condom distribution program during NACPII. Least impact is found among students and laborers. The heterosexual route, IDU and blood, and blood products were stable while the homosexual route and parent to child (PPTCT) was still on the higher side.

\section{Conclusion}

National intervention programs started during NACPII and continued during NACPIII have greatly impacted in stabilizing or even reducing the epidemic. However, more intensified epidemiological studies should be

\footnotetext{
* Correspondence: skarorain@gmail.com

Integrated Counseling and Testing Center (ICTC), Department of Immunopathology, PGIMER, Chandigarh, India
}

carried out which will help planning intervention projects to interrupt and control the transmission of HIV/ AIDS.

Published: 27 May 2014

\section{doi:10.1186/1471-2334-14-S3-P23}

Cite this article as: Metha et al:: Time trend analysis of HIV infection showing impact of national programs in an ICTC set up in a tertiary care hospital in North India. BMC Infectious Diseases 2014 14(Suppl 3):P23.
Submit your next manuscript to BioMed Central and take full advantage of:

- Convenient online submission

- Thorough peer review

- No space constraints or color figure charges

- Immediate publication on acceptance

- Inclusion in PubMed, CAS, Scopus and Google Scholar

- Research which is freely available for redistribution

\section{() Biomed Central}

